\title{
Müllerian Adenosarcoma of Ovary with Heterologous Elements: a rare case in a girl
}

Jiwei $\mathrm{Li}^{1}$, Lan Shen ${ }^{1}$, rui du ${ }^{2}$, Meifen Wang ${ }^{1}$, and yucheng xie ${ }^{1}$

${ }^{1}$ Kunming Medical University

${ }^{2}$ Guangzhou Medical University

June 11, 2020

\section{Hosted file}

MAs (brief) . doc available at https : //authorea.com/users/332317/articles/458780-m\%C3\%BCllerianadenosarcoma-of-ovary-with-heterologous-elements-a-rare-case-in-a-girl

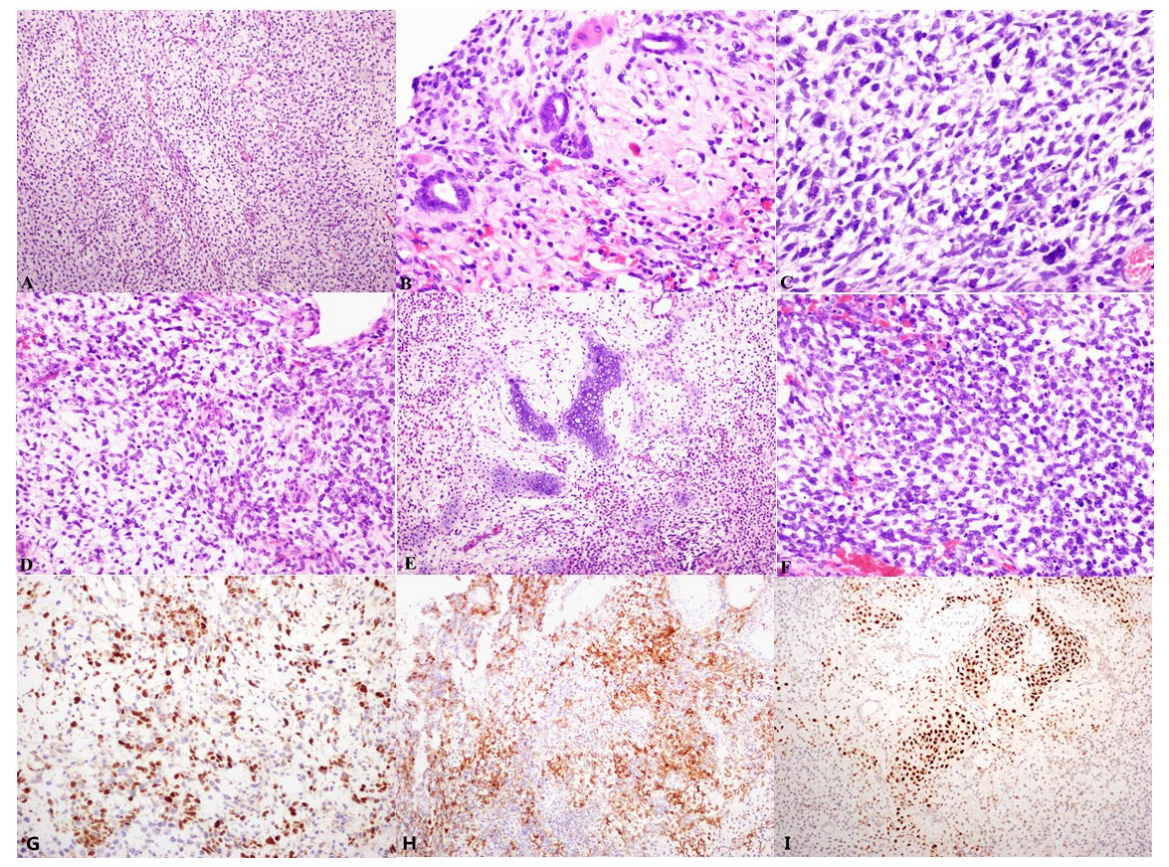

